\title{
PSYCHOLOGICAL LITERACY FOR ALL: AN OVERVIEW OF THIS 'LITERACY' AND HOW IT IS RELEVANT FOR STUDENTS OF ALL DISCIPLINES
}

\author{
J. Taylor \\ Bournemouth University (UNITED KINGDOM)
}

\begin{abstract}
Over the past 20 years a number of educational 'literacies' have become recognized as learning outcomes in schools and universities [1]. The term 'psychological literacy' relates to an individual's ability to apply an understanding of psychology to their everyday personal, social and work lives. The greatest development and application of psychological literacy has been within psychology education, however this article proposes that an understanding of psychological literacy is relevant to students across all disciplines. Indeed, many undergraduate courses already include elements of psychology (for example, medical education and teacher-training). It has been proposed [2], that psychology as a discipline has much to offer for the public good, as many of the problems in society today relate to human behavior (e.g. work stress, environmental damage, obesity, addiction). This article reviews examples of ways that psychological literacy can be developed, taught and assessed across disciplines and how psychological literacy can be applied within society. One of the key resources, a compendium of case studies [3], is reviewed to demonstrate practical activities to incorporate psychological literacy into curricula. Further inter-disciplinary discussion is suggested among educators to identify best practice in developing psychological literacy across disciplines and thereby within society.
\end{abstract}

Keywords: Psychological literacy, inter-disciplinary, training, meta-cognition, applied psychology, societal issues

\section{INTRODUCTION}

Written, verbal and numerical literacies have long been an intended outcome of formal and informal learning processes, and recently a number of new educational 'literacies' are being recognized as key learning outcomes in schools and universities [1]. 'Information literacy' is defined as, "the ability to think critically and make balanced judgements about any information we find and use. It empowers us as citizens to develop informed views and to engage fully with society" [4]. 'Media literacy' has been defined as the ability to, "decode, evaluate, analyze, and produce both print and electronic media" ( $p$. 79) [5]. 'Digital literacy' has been defined [6] as, "the ability to use information and communication technologies to find, evaluate, create, and communicate information, requiring both cognitive and technical skills".

Around 10 years ago a number of key academic books and articles were published and 'psychological literacy' became a recognized term in psychology education (e.g. [7], [8]). The term 'psychological literacy' relates to an individual's ability to apply an understanding of psychology to their everyday personal, social and work lives. Psychological literacy has been defined by [9] as, "applying psychological principles to personal, social, and organizational issues in work, relationships, and the broader community" and "being insightful and reflective about one's own and others' behavior and mental processes" (p. 11). Although naturally the greatest development and application of psychological literacy has been within psychology education, it is proposed in this article that an understanding of psychology is relevant to students across all disciplines. Many undergraduate courses already include elements of psychology, for example, medicine, teacher training, media, english language, law, biology, health and business studies. However, these elements are often minimal and focus on content, rather than the potential application of psychology within and outside of education.

Psychological literacy can play an important role in diverse parts of society and if more students have an understanding of psychology and the ways that it could be applied, this could have positive impacts on ways of working for our future workforce. Consider the work of teachers, doctors, managers, health care assistants, economists, engineers, IT personnel, social workers and legal personnel. For each of these employees, psychological literacy can help support their understanding of people regarding the 
way they think and behave. Examples include clearer communication with patients and clients, more effective teaching and learning, more scientific evaluation of witness evidence, and the design and implementation of computing systems that are more user-friendly. According to [2], psychology as a discipline has much to offer society, and the current need is great, as many of the problems in society today relate to human behavior. For example, knowledge regarding the mechanisms of attitudes and persuasion can enhance understanding of behavior change processes for environmental issues and health-related behaviors. Also, a focus on evidence-based research can be used to understand interventions to change these behaviors. Many other problems today relate to individual psychological distress or low levels of wellbeing. So for example, knowledge regarding the biological basis of stress could help students to understand why and how different techniques work to alleviate stress. An understanding of psychology can also help students better understand their personal lives, for example, their own individual development and growth.

Psychological literacy is about more than understanding and applying psychological knowledge, useful transferable skills can also be developed through an understanding of psychology. For example, if students have opportunities to acquire and reflect on metacognitive capacities, they will be better able to develop solutions to problems in their own lives. Illustrating to students how humans learn, can help students to reflect upon their own learning preferences and style; leading to development of effective techniques for note-taking, revising and sitting exams as well as in the longer term to develop a capacity for life-long learning. Communication and group skills can be improved if students have some understanding of the underlying processes (e.g. groupthink, social loafing and interpreting nonverbal cues). An understanding of the research process and the development of research skills used in psychology can be useful for students of non-scientific disciplines. The ability to relate theory, hypotheses, research methods and results to their implications is helpful for any activity involving humans. For example, highlighting the potential application of psychological findings allows students to fully appreciate the contribution that psychology can make to their working lives (e.g. understanding a research report and statistics). Being critical about the way statistics are used can help understand reports in the media and in advertising.

\section{DEVELOPING PSYCHOLOGICAL LITERACY FOR PSYCHOLOGY STUDENTS}

In 2007, an influential report on 'The Future of Psychology Education' [10] jointly produced by the British Psychological Society (BPS), the Association of Heads of Psychology Departments (AHPD) and the Higher Education Academy (HEA) called for all UK Psychology degrees to include psychological literacy. Following this report, there was increasing interest in developing psychological literacy within the UK from the education and psychology communities. Since then, academics have been introducing the concept to their students, however there have been relatively few resources published to help develop practical activities. To address this need, a compendium of case studies was collated, to demonstrate examples of practical activities that were currently being used in the UK [3].

The majority of case studies in the compendium discuss the ways that developing psychological skills can enhance future employability. The benefits of including discussions of employability at all levels of the degree and not just in the final year are illustrated. Over half of the case studies report the many psychological skills developed when students take part in a work placement or similar activity such as volunteering or work based learning. Examples of ways to incorporate this activity into curricula are provided. The majority of activities occurred in units that developed transferable skills, for example, units called 'psychological enquiry' and 'psychology in everyday life'. Teaching and learning activities were varied and included many interactive techniques, such as group work, and enquiry-based or project-based learning. One of the case studies highlights the many positive outcomes from an activity where students from different year groups collaborated together in a peer mentoring scheme. Another case study involved students evaluating alternative courses of action when presented with a novel human-based problem and to design an intervention or solution; a useful skill for life outside of and following the degree. The majority of case studies address the key psychological attribute of reflection and discuss activities to develop this skill. Not all units covering psychological literacy activities were assessed. The authors recommend that when designing assessment, it is useful to make links to the course intended learning outcomes, and consider university quality assurance procedures and professional body requirements. Psychological literacy was mainly covered at level six and mainly in optional units or voluntary extra-curricular activities, therefore missing out on the potential value to all students. One of the key suggestions from the authors, was that psychological literacy should be 
embedded throughout an undergraduate degree to realize the developmental benefits and ensure all students come into contact with the concept.

\section{CHALLENGES WHEN DEVELOPING PSYCHOLOGICAL LITERACY IN NON- PSYCHOLOGY STUDENTS}

There are a few issues to consider when considering development of psychological literacy for students in other disciplines. Non-psychology students can learn about psychology in many ways and the content and way it is taught can affect their perception of the discipline and the extent that they will develop psychological literacy. Also, psychologists can have a range of views about the value of teaching psychology to non-psychology students. These two issues will be discussed in this section, and research recommending inter-disciplinary collaboration will be presented.

Students can choose psychology as a formal 'minor' to their major subject, or they may study one or two modules. Degrees where psychology units are part of the main curricula include medical education and teacher training. The way psychology is taught also varies; it can be bespoke to a discipline, or psychology and non-psychology students can be taught together. However, there are few guidelines on how to teach psychology to non-psychology students. According to [11], $70 \%$ of departments did not refer to national or international guidance or criteria when developing psychology curricula for non-psychology students, suggesting they may depend on the demands from the nonpsychology discipline. These researchers [11] call for initiatives to develop psychology curricula for non-psychologists in different academic disciplines. To help design materials and curricula for nonpsychologists, [12] propose considering a number of criteria. These are that it should be: specific to the profession; specific to the needs and work processes of the other discipline; and limited to the professional field of the other discipline. They also caution that although psychology curricula needs to be limited regarding its breadth, it should maintain the depth and the different perspectives required for understanding psychological phenomena. In their conclusion, [12] propose that psychologists needed to collaborate with experts from non-psychology disciplines, through informal exchanges of information as well as more formal mechanisms, to identify the requirements, problems and challenges of nonpsychology disciplines. In this way, there could be a balance between what psychology can provide and what other disciplines require.

'Service teaching', where psychology educators become involved in teaching psychology to students studying other disciplines is not new. The levels of service teaching vary between universities and between countries. In the UK and the Netherlands, it is relatively common for psychology departments to deliver psychology material to other faculties. While in the Czech Republic, it is not at all common to teach psychology to other disciplines [12]. When psychology content is requested from other departments, sometimes psychology teachers do not value or enjoy this experience; preferring to teach psychology to psychology students. A survey was conducted [11] of European psychology departments, regarding teaching psychology to non-psychology students and the results indicated some negative opinions about the usefulness of psychology for these students. When asked whether different disciplines would benefit from psychology: no departments stated that humanities students would benefit, only $1.5 \%$ stated that science students would benefit, while $22 \%$ thought psychology useful for medical and health science students. However, the results were based on a small survey and further research is needed to test the generalizability of these findings.

\section{EXAMPLES WHERE PSYCHOLOGY AND PSYCHOLOGICAL LITERACY HAVE BEEN FORMALLY TAUGHT AND ASSESSED ACROSS DISCIPLINES}

Despite some of the challenges discussed in section 3 , this section will review some examples where psychological literacy has been successfully developed, taught and assessed across other disciplines. Two fields which seem more advanced in their development of psychological literacy are teacher training and medical education. Also included is a brief discussion of the field of computing, which is increasingly drawing on and including psychological concepts within curricula.

\subsection{Teacher training}

Areas of psychology important for teacher training relate to how children learn and how they develop cognitively, biologically and socially from birth to young adult. For example, teaching the topic of intrinsic and extrinsic motivation helps teachers understand how children can be motivated to learn and achieve. Although it is important to illustrate to teachers the potential psychological issues that 
children may present with, it is important to recognize that non-psychology students are not being trained to practice as a psychologist. So if a teacher is aware that a student may be presenting with a learning difficulty, they would need to share this observation with an educational psychologist who would then diagnose an issue and prepare a treatment or plan or therapy. The aim of a study by [13] was to identify topics from psychology that would be the most important for teachers to understand. Using a mixed methods approach they initially asked a range of teacher educators (including psychologists and non-psychologists) to evaluate the importance of different psychological topics to teaching. Following this, they used the Delphi method and asked 48 experts to select the topics which they thought should be taught and this produced a ranking of topics. The authors provide a comprehensive selection of topics to include in a teacher education curriculum, and suggest that if used widely this would help to standardize the curriculum.

\subsection{Medical education}

Although psychology has much relevance for health and allied professions, [14] notes that psychology was not formally included within medical education in the USA until the 1970s. Despite many efforts throughout the preceding 70 years, [14] discusses reasons for the resistance to incorporating psychology in medical training; during this time, psychologists were merely considered as an adjunct in medical practice. An initial area of teaching covered ways to improve the doctor-patient relationship and included how the doctor could communicate effectively to gather accurate information from the patient and explain clearly what the medical problem is. It is not just the style of communication that is important, but based on psychological research, presenting alternative potential treatment plans helps patients to understand why a choice was made. Theories of motivation and compliance were included to enable doctors to apply this to encourage patients to follow a treatment plan (e.g. eating more healthily and exercising) and to take medication at the right time and in the correct quantity. Other areas covered basic mental processes and indicators to recognize deviations from these 'normal' processes. Addressing the lack of an agreed medical education curriculum relating to psychology in the UK, [15] attempted to develop an evidence-based behavioral sciences curriculum for undergraduate medical education. By collecting the views from experts in psychology, medicine and medical education, they produced a core psychology curriculum for undergraduate medical teaching and highlighted the importance of collaborating with key stakeholders.

\subsection{Computing practice and education}

Psychologists have recently been successful in influencing practice within the field of computing, especially within the branch of human-computer interaction. Cognitive psychology can be taught so that software designers take into account perception, attention and memory. While social psychology can be used to understand the many issues involved in designing for humans to communicate interpersonally and in groups via technology. Additionally, an understanding of individual differences is important to design computer systems that can be used by a variety of people, taking into account psychological and physical differences. In an early example, [16] highlighted the importance of taking into account the needs of students, in terms of making links to the computing profession and domain when designing and presenting psychological materials so that it is relevant and students don't need to work out why certain theories or findings are relevant. In a later example, [17] showed how explicitly explaining the relevance and potential application of psychology could help to avoid design errors in the field of cybersecurity education.

\section{CONCLUSIONS}

Further inter-disciplinary discussion and development is needed among educators, to design activities that can be used to develop psychological literacy across disciplines, and ultimately to encourage students to apply psychological literacy within society. Also, there is a need to identify valid and reliable measurements of psychological literacy that can be used across disciplines, to evaluate and assess the effectiveness of these activities. At a more central level, national psychology bodies are making increasing efforts to highlight the usefulness and impact of psychological research and practice for society, e.g. they are encouraging and developing formal and informal links between psychologists and journalists and government bodies. In these ways, it is hoped that psychological literacy will become a key learning outcome for courses across many disciplines, much as information literacy and media literacy have done recently. 


\section{REFERENCES}

[1] S. Abram, "Scaffolding the new social literacies", Multimedia and Internet@Schools, vol. 15, no. 2, pp. 21, 2008.

[2] J. Cranney, "Why psychological literacy is relevant to all psychology graduates, regardless of career destination", ICOPE Conference, University of Dhaka, Bangladesh, 22 - 23 March, 2019.

[3] J. Taylor and J. Hulme, "Introducing a compendium of psychological literacy case studies: Reflections on psychological literacy in practice", Psychology Teaching Review, vol. 21, no. 2, pp. 25-34, 2015.

[4] J. Secker, "A New Definition of Information Literacy", 2018. Retrieved on 25 April 2019 from https://www.cilip.org.uk/news/421972/What-is-information-literacy.htm

[5] P. Aufderheide, "Media Literacy: A report of the national leadership conference on media literacy", Aspen, CO: Aspen Institute, 1993.

[6] The American Library Association Digital Literacy Task Force, "Defining digital literacy", 2019. Retrieved $18^{\text {th }}$ April 2019 from https://literacy.ala.org/digital-literacy/

[7] D. F. Halpern (Ed.). "Undergraduate Education in Psychology: A Blueprint for the Future of the Discipline", Washington, DC: American Psychological Association, 2010.

[8] J. Cranney, \& D. S. Dunn (Eds.), "The Psychologically Literate Citizen: Foundations and global perspectives". New York: Oxford University Press, 2011.

[9] T.V. McGovern, L. Corey, J. Cranney, J., W.E. Dixon, J.D. Holmes, J.E. Kuebli, K.A. Ritchey, R.A. Smith \& S.J. Walker, "Psychologically literate citizens". In D. F. Halpern (Ed.), Undergraduate Education in Psychology: A Blueprint for the Future of the Discipline (pp. 9-27). Washington, DC: American Psychological Association, 2010.

[10] A. Trapp, P. Banister, J. Ellis, R. Latto, D. Miell, and D. Upton, "The Future of Undergraduate Psychology in the United Kingdom". York: Higher Education Academy, 2011. Retrieved $24^{\text {th }}$ April 2019 from https://www.heacademy.ac.uk/knowledge-hub/future-undergraduatepsychology-united-kingdom

[11] S. Dutke \& K. Epler, "Psychology in the academic education of non-psychologists: a survey among European psychology departments", In M. Kramer, U. Weger \& M. Zupanic (Eds), Didactics of Psychology and Evaluation (pp.19-26). Aachen, Germany: Shaker, 2014.

[12] S. Dutke, H. Bakker, L. Sokolová, I. Stuchlikova, S. Salvatore \& I. Papageorgi, "Psychology curricula for non-psychologists? A framework recommended by the European Federation of Psychologists' Associations' Board of Educational Affairs", Psychology Learning \& Teaching, in press.

[13] H. Lohse-Bossenz, O. Kunina-Habenicht \& M. Kunter, "The role of educational psychology in teacher education: expert opinions on what teachers should know about learning, development and assessment", European Journal of Psychology of Education, vol. 28, pp.1543-1565, 2013.

[14] W. Pickren, "Psychology and medical education: a historical perspective from the United States", Indian Journal of Psychiatry, vol. 49, pp. 179-181, 2007.

[15] L. Cordingley, S. Peters, J. Hart, J. Rock, L. Hodges, J. McKendree \& C. Bundy. "What psychology do medical students need to know? An evidence based approach to curriculum development", Health and Social Care Education, vol. 2, pp. 38-47, 2013.

[16] J. Taylor, "Teaching psychology to computing students", Psychology Teaching Review, vol. 14, no.1, pp. 21-29, 2008.

[17] J. Taylor, H. Thackray, S. Hodge, and J. McAlaney, "Introducing psychological concepts and methods to cybersecurity students". In J. McAlaney., L.A. Frumkin, and V. Benson (Eds), Psychological and Behavioral Examinations in Cyber Security, pp.98-108. Hershey, PA: IGI Global, 2018. 